\title{
ONLINE PROBLEM POSING UNTUK MENINGKATKAN KEMAMPUAN MEMAHAMI MATERI BERBAHASA INGGRIS PADA PERKULIAHAN BILINGUAL MAHASISWA JURUSAN PENDIDIKAN MATEMATIKA RKBI UNIVERSITAS PENDIDIKAN GANESHA
}

\author{
Ni Made Sri Mertasari, I Made Candiasa \\ Fakultas Pendidikan MIPA \\ Universitas Pendidikan Ganesha, Singaraja, Indonesia
}

\begin{abstract}
Abstrak
Portal web dengan fasilitas online problem posing telah dicoba dikembangkan dan dipasang pada situs web Program Pascasarjana Universitas Pendidikan Ganesha. Proses ini memberikan beberapa pengalaman kepada para mahasiswa. Pertama, program memberikan pengalaman menjelajahi internet kepada mahasiswa. Kedua program memberi pengalaman mendesain informasi berbasis hiperteks kepada mahasiswa. Ketiga, program memberikan keuntungan yang dimiliki pembelajaran berbasis komputer, seperti bebas konteks, bebas konvensi sosial, tidak terlalu terikat waktu, dan mampu beradaptasi dengan kemampuan mahasiswa secara individu. Media tersebut telah diujicoba untuk diterapkan secara terbatas pada perkuliahan bilingual mahasiswa Jurusan Pendidikan Matematika RKBI. Ditemukan sementara bahwa, mahasiswa memberikan respon positif terhadap perkuliahan melalui portal web dengan online problem posing. Mahasiswa lebih termotivasi untuk melakukan problem posing dengan lugas tanpa takut salah dan berupaya memberikan tanggapan terhadap pendapat temannya dengan pengetahuan dan kemampuan bahasa Inggris yang dimiliki.
\end{abstract}

Kata-kata kunci: portal web, online problem posing, perkuliahan bilingual

\begin{abstract}
Web portal with online problem posing facility has been implemented and installed at website of Graduate Program Universitas Pendidikan Ganesha. This facility will give several advantages. First of all, this facility will give experince in looking for the information at internet environment. Furthermore, this kind of facility will give experince to design hypertext based information. Finally, this kind of facility will give more flexible instructional process, such as anonym, private, contex free, less influenced by social conventions, and can be adapted to the individual student capability. Web portal with online problem posing facility has been tried out at bilingual course for international class of educational mathematics students. It is found that, students have positive respons to the course by using web portal with online problem posing facility. Web portal with online problem posing facility is hoped can be implemented widely, in order to give more opportunities to student to choose instructional model.
\end{abstract}

Keywords; web portal, online problem posing, bilingual course.

\section{PENDAHULUAN}

Rencana strategis Kementerian Pendidikan Nasional telah menetapkan beberapa sasaran strategis antara lain: 1) sekurang-kurangnya $50 \%$ kabupaten/ kota memiliki SD SBI atau RSBI; 2) sekurangkurangnya $60 \%$ kabupaten/kota memiliki SMP SBI atau RSBI; 3) Sekurang- kurangnya $40 \%$ SD/SDLB dan $60 \%$ SMP/SMPLB melaksanakan e-learning; 4) sekurang-kurangnya $60 \%$ kabupaten/kota memiliki SMA dan SMK SBI atau RSBI; dan 5) sekurang-kurangnya $75 \%$ SMA/SMLB dan $70 \%$ SMK melaksanakan e-learning (Depdiknas, 2010). Situasi nyata di lapangan, khsusnya di Bali, sampai saat ini 
sudah ada beberapa sekolah yang berstatus $\mathrm{RSBI}$, namun belum ada yang mencapai status SBI. Kabid. Dikmen Dinas Pendidikan dan Olahraga Provinsi Bali seperti dimuat Majalah Tokoh No. 585/Tahun XI menyatakan bahwa $\mathrm{SBI}$ belum berhasil diwujudkan di Bali. Kendalanya adalah keterbatasan guru dan teknologi informasi.

Mencermati saran untuk

mengangkat guru baru sesuai kriteria, Universitas Pendidikan Ganseha sebaga lembaga pendidikan tenaga kependidikan sudah mengambil langkah antisipasi dengan membuka program rintisan kelas bertaraf internasional (RKBI) untuk beberapa jurusan kependidikan. Perkuliahan di RKBI berlangsung dengan bilingual, bahasa Inggris dan bahasa Indonesia. Lulusan yang dihasilkan diharapkan mampu mengajar di $\mathrm{RSBI}$ atau SBI yang melaksanakan pembelajaran dengan bilingual. Selain itu, $\mathrm{RKBI}$ juga diharapkan menghasilkan lulusan yang berdaya saing global, seperti ditetapkan pada rencana strategis Kementerian Pendidikan Nasional 20102014 sebagai salah satu tujuan strategis yakni mengembangkan kebijakan yang kondusif untuk menghasilkan perguruan tinggi berdaya saing global (World Class UniversityMCU). Oleh karena itu, pemanfaatan TIK dalam perkuliahan harus mendapat perhatian utama.

Pemanfatan TIK dengan berbagai bentuk variasinya wajib dilakukan dalam pembelajaran pada sekolah-sekolah dengan staus RSBI atau SBI, serta pada RKBI di perguruan tinggi. Peserta didik dapat mengakses materi dari berbagai situs secara simultan, baik berupa teks, audio, atau video. Siswa dapat berinteraksi dengan guru dan siswa dari berbagai cara. Siswa dapat secara mandiri mengatur pembelajarannya dan guru dapat meningkatkan kemampuannya untuk mengelola pembelajaran melalui kolaborasi dengan koleganya. Anderson (2006) menemukan bahwa e-learning membuat siswa belajar dengan nyaman dengan berkomunikasi satu sama lain secara online.

E-learning juga memberikan keutungan bagi guru dapat bekerja pada komunitas on-line. Komunitas belajar on-line adalah kelompok belajar yang didasari oleh komitmen dan kepentingan bersama untuk belajar secara kolaboratif dengan difasilitasi lingkungan belajar maya (Ke \& Hoadley, 2009). Apabila guru menumui masalah dalam pembelajaran, maka mereka dapat menghubungi para koleganya lewat dunia maya. Sofos \& Kostas (2009) menemukan bahwa proses keterlibatan dalam komunitas on-line secara praktis telah mampu meningkatkan kemampuan guru dalam mengelola web pembelajaran, sehingga memenuhi kriteria web pembelajaran standar.

TIK dalam e-learning di RKBI memiliki dua sasaran. Pertama, TIK harus mampu meningkatkan hasil belajar dan kedua, TIK harus mampu meningkatkan kemampuan siswa memahami materi perkuliahan berbahasa Inggris. Pada penelitian sebelumnya telah dikaji dikaji pemanfaatan modul web dengan pola insentif untuk meningkatkan kemampuan mahasiswa memahami materi berbahasa Inggris dalam perkuliahan bilingual mahasiswa Jurusan Pendidikan Matematika RKBI Universitas Pendidikan Ganesha. Modul web dengan pola insentif dipasang pada portal web, sehingga mahasiswa dapat mengakses secara on-line.

Pada penelitian ini dicoba dikaji portal web dengan fasilits online problem posing untuk meningkatkan kemampuan memahami materi berbahasa Inggris pada perkuliahan bilingual mahasiswa Jurusan Pendidikan Matematika RKBI Universitas Pendidikan Ganesha. Portal web dengan fasilitas online problem posing dikembangkan dan dipasang pada portal $e$ learning melalui penelitian rancang bangun. Efektivitas fasilitas online problem posing dikaji melalui penelitian tindakan kelas pada mahasiswa Jurusan Pendidikan Matematika RKBI. 
Pertanyaan yang sering muncul dalam pembelajaran matematika adalah mengapa siswa sangat jarang bertanya selama pembelajaran matematika? Salah satu jawaban dari pertanyaan tersebut adalah akibat siswa tidak menyadari masalah yang dihadapi. Rendahnya kemampuan siswa untuk menyadari permasalahan dalam pembelakaran matematika dapat terjadi karena siswa selama pembelajaran siswa hanya dilatih untuk penyelesaian masalah (problem solving). Xia, Lu dan Wang (2008) menyatakan bahwa,dalam pembelajaran matematika, bukan hanya kemampuan pemecahan masalah yang harus diupayakan melainkan kreativitas matematika juga harus didapatkan, oleh karena itu, pembelajaran matematika harus terdiri dari dua aspek, yaitu pemecahan masalah dan pengajuan masalah (problem posing).

Problem posing pertama kali muncul
pada tulisan Paolo Freire tentang
Pendidikan untuk Kaum Tertindas

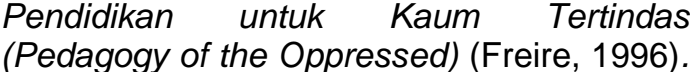
Perhatian Freire terfokus pada penyadaran kaum tertindas. Kaum tertindas didorong untuk berjuang demi hak kemanusiaannya yang diingkari kaum penindas. Teori pendidikan problem posing diterapkan oleh Freire untuk menyadarkan kaum tertindas sekaligus melawan teori pendidikan konsep bank yang menjadi kesayangan kaum penindas. Pendidikan konsep bank menganggap siswa sebagai perahu kosong yang harus diisi dengan pengetahuan, seperti mendepositokan uang di bank.

Problem posing dalam pembelajaran matematika dapat diartikan sebagai pengajuan masalah. Apabila pembelajaran matematika dilaksanakan dengan menerapkan model problem posing, maka siswa diwajibkan untuk mengajukan soal atau masalah. Agar dapat mengajukan masalah, terlebih dahulu siswa harus merumuskan atau menyusun masalah. Artinya, dalam pembelajaran matematika dengan model problem posing siswa wajib merumuskan dan mengajukan masalah. Masalah dalam pembelajaran matematika dapat berupa soal atau pertanyaan. Masalah yang diajukan dapat berupa masalah yang benar-benar baru disusun siswa, masalah yang dimodifikasi dari masalah lain yang identik, atau bahkan masalah-masalah yang merupakan bagian dari masalah yang lebih besar.

Problem posing mengacu pada menciptakan masalah yang benar-benar baru atau merevisi masalah yang harus diselesaikan (Silver, 1994). Problem posing dapat terjadi sebelum, saat, atau sesudah penyelesaian suatu masalah. Artinya, dalam upaya menyelesaikan suatu masalah, siswa dapat saja mengajukan pertanyaan sebelum memulai penyelesaian masalah tersebut. Demikian pula halnya selama penyelesaian masalah, apabila dipandang perlu, maka siswa dapat mengajukan pertanyaan atau masalah yang terkait. Bahkan setelah penyelesaian masalah diperoleh, siswa dapat mengajukan masalah lain yang identik. Begitu seterusnya, sehingga setiap tugas dapat menimbulkan satu atau lebih tugas yang lain lain. Tugas yang terbuka dalam proses pengerjaan dan penyelesaian dapat meningkatkan kemampuan berpikir tingkat tinggi siswa (De Lange dalam Lin, 2008).

Stoyanova (1996) mendefinisikan
problem posing dalam pembelajaran matematika sebagai proses perumusan masalah matematika berbasiskan situasi konkrit. Dengan memanfaatkan ketrampilan berpikir yang telah dimiliki, siswa dapat memanfaatkan situasi yang ada untuk merumuskan kembali atau merevisi masalah yang diberikan. Ketrampilan problem posing dapat dikembangkan dengan memberikan siswa masalah yang tidak terstruktur (illformulated) atau masalah yang tidak sepenuhnya terstruktur (partially formulated problem) dan memintya siswa untuk merumuskannya kembali (Silver, 1994). English (1997) menyatakan bahwa aktivitas utama dari problem posing adalah 
menyusun pertanyaan baru berdasarkan tugas matematika yang diberikan.

Aktivitas problem posing dalam pembelajaran matematika memerlukan beberapa ketrampilan seperti berikut. 1) Menerapkan strategi pemecahan masalah untuk menyelidiki dan menyelesaikan masalah yang diajukan. 2) Merumuskan masalah berdasarkan kondisi sehari-hari dan kondisi matematis. 3) Menerapkan pendekatan lengkap untuk mengajukan masalah dalam situasi matematis. 4) Memahami keterkaitan antara topik-topik dalam matematika. 5) Menggeneralisasikan penyelesaian dan strategi penyelesaian kepada situasi masalah yang baru. 6) Mengajukan maslah yang lebih kompleks berdasarkan masalah yang sederhana. 7) Mengajukan masalah matematika pada bidang penerapan yang berbeda. 8) Kemampuan untuk menyusun pertanyaan untuk melengkapi strategi pengajuan masalah, seperti: a) bagaimana saya bisa menyelesaikan masalah, dapatkah saya mengajukan pertanyaan yang lain, berapa penyelesian yang dapat saya temukan.

Keberadaan fasilitas komunikasi bermedia komputer di dunia pendidikan sudah cukup lama, tetapi pada awalnya masih terbatas pada penggunaan untuk sarana komunikasi antar para peneliti dalam bentuk pertukaran informasi berwujud teks. Perkembangan layanan komunikasi bermedia komputer berkembang pesat sejalan dengan perkembangan komputer menjadi hypermedia, yaitu jaringan komputer yang tidak hanya mampu menyajikan teks tetapi sudah mampu menyajikan berbagai informasi melalui berbagai media komunikasi, seperti suara, gambar, grafik, dan video (McKnight, dkk., 1996). Perkembangan layanan tersebut membuat komunikasi berbasis komputer menjadi semakin populer. Belakangan ini komunikasi pembelajaran berbasis komputer sudah amat populer dengan memanfaatkan e-mail, facebook, dan situs web yang khusus menyajikan informasi pendidikan. Oleh karena itu, istilah e-pembelajaran yang merupakan terjemahan dari e-learning sudah sangat populer di kalangan masyarakat.

Website, chatting atau e-mail memberi peluang kepada guru untuk menyampaikan pertanyaan atau masalah kepada siswa melalui keyboard komputer. Sebaliknya, siswa menerima pertanyaan melalui tampilan teks, grafik, gambar, atau video di monitor komputer. Selanjutnya, siswa memberikan jawaban atau tanggapan dengan memanfaatkan keyboard atau mouse, dan guru menerima jawaban atau tanggapan tersebut melalui monitor. Komputer dalam hal ini, dapat dibuat untuk bekerja lebih cepat dan lebih cermat daripada guru. Alasannya, respon siswa dapat dikoreksi langsung, sehingga dapat diberikan skor secara cepat atau bahkan diberikan umpan balik secara cepat pula. Sebaliknya, Website, chatting atau e-mail juga memberi peluang kepada siswa untuk mengajukan pertanyaan atau masalah (online problem posing) kepada guru dan siswa lainnya melalui keyboard komputer.

On-line problem posing dilakukan dalam upaya mengintegrasikan teknologi informasi sebagai media pembelajaran dengan inovasi di bidang desain instruksional. Teknologi yang amat canggih sekalipun tidak dapat memberikan hasil yang optimal dalam pembelajaran apabila tidak diintegrasikan dengan inovasi-inovasi dalam bidang pembelajaran. Light (2010) menganjurkan bahwa perubahan dalam bidang pembelajaran harus dilakukan di kelas sambil membenahi infrastruktur karena alat bantu berupa teknologi baru tidak cukup jika tidak inovasi pembelajaran profesional dari guru. Terkait dengan anjuran Light di atas, pendidikan calon guru disarankan untuk memanfaatkan laboratorium virtual (laboratorium online) karena calon guru sekarang cenderung lebih banyak memanfaatkan teknologi dalam pembelajarannya (Bhukuvhani dkk, 2010).

Memperhatikan uraian di atas, tepat kiranya untuk mahasiswa Jurusan Pendidikan Matematika RKBI Universitas 
Pendidikan Ganesha diujicobakan perkuliahan dengan online problem posing, yang mana di dalamnya terdapat perpaduan antara inovasi di bidang teknologi dan inovasi di bidang desain pembelajaran. Perkuliahan dengan online problem posing sekaligus melatih mahasiswa untuk lebih memahami teknologi informasi yang lebih baru dan lebih banyak memanfaatkan teknologi informasi tersebut dalam pembelajaran. Hal ini sangat perlu disadari karena teknologi informasi di luar sekolah berkembang lebih cepat (Mabry, Radlick \& Doane, 2010). Selain itu, isu utama untuk mengintegrasikan teknologi ke dalam pembalajaran adalah akses ke teknologi dan kendala memanfaatkan teknologi tersebut (Kotrlik \& Redmann, 2009). Oleh karena itu, disarankan agar guru yang akan menyelenggarakan pembelajaran di kelas lebih banyak dibantu dalam pemanfaatan teknologi informasi. Salah satu caranya adalah dengan lebih awal membekali para calon guru.

\section{METODE PENELITIAN}

Penelitian ini secara utuh terdiri dari dua tahap. Penelitian tahap pertama merupakan penelitian rancang bangun untuk melengkapi portal web e-learning UNDIKSHA agar mampu memfasilitasi online problem posing dan penelitian tahap kedua merupakan penelitian tindakan kelas untuk mengkaji efektivitas online problem posing pada perkuliahan bilingual mahasiswa Jurusan Pendidikan Matematika RKBI untuk meningkatkan kemampuan mahasiswa memahami materi dalam bahasa Inggris.

Penelitian tahun ini merupakan penelitian tahap pertama, yakni pembangunan perangkat lunak (software) dengan sasaran akhir berupa terbangunnya sebuah perangkat lunak sesuai dengan spesifikasi yang ditetapkan, yakni portal web perkuliahan dengan fasilitas online problem posing. Oleh karena itu, metode yang digunakan mengikuti paradigma dalam pengembangan perangkat lunak, yakni paradigma prototyping. Paradigma ini dipilih dengan alasan pengembangan perangkat lunak dikerjakan secara terpadu antara pakar materi perkuliahan, pakar teknologi perkuliahan dan pakar di bidang web. Prototyping merupakan sebuah proses yang memungkinkan pengembang untuk bekerjasama membuat model perangkat lunak yang diinginkan. Model perangkat lunak tersebut kemudian dievaluasi dan diperbaiki secara bersama-sama. Apabila sudah dianggap layak, maka perangkat lunak tersebut langsung diproduksi, sedangkan apabila masih ada kekurangan, maka dilakukan perbaikan.

Perangkat lunak portal web dengan fasilitas online problem posing yang sudah dikembangkan diujicoba secara terbatas pada perkuliahan bilingual mahasiswa jurusan Pendidikan Matematika. Pada akhir uji coba mahasiswa diwajibkan memberikan tanggapan terhadap pelaksanaan perkuliahan dengan portal web yang dilengkapi dengan fasilitas online problem posing. Tanggapan yang dimaksud menyangkut informasi di seputar pengoperasian serta persepsi mahasiswa terhadap perkuliahan dengan portal web disertai fasilitas online problem posing.

\section{HASIL DAN PEMBAHASAN}

Portal web e-learning dengan fasilitas online problem posing telah berhasil dikembangkan. Portal dikembangkan menggunakan bahasa pemrograman PHP dan sebagai basis-data pendukung digunakan Mysql. Komponen pendukung lainnya, seperti desain grafis, desain web, dan animasi masing-masing dikembangkan dengan paket program yang relevan. Desain grafis dikembangkan menggunakan Adobe Photoshop Cs, desain web dikembangkan menggunakan Macromedia Dreamweaver $M x$, dan animasi dikembangkan menggunakan Macromedia Flash 8. Selama proses uji coba, portal web e-learning yang sudah dikembangkan dijalankan di web server IBM System X3650, P III Xeon 4 CPU 2Ghz, memory $2 G B$. Tampilan depan dan 
fasilitas layanan forum yang ada pada sistem antara lain adalah adalah sebagai berikut.



Portal web dengan fasilitas online problem posing dipasang pada situs web Program Pascasarjana Universitas Pendidikan Ganesha. Beberapa mahasiswa mencoba mengakses pembelajaran dari workstation masing-masing. Komunikasi pembelajaran dilakukan melalui jaringan komputer. Mahasiswa melakukan online problem posing sesuai materi pembelajaran yang tersaji. Setelah uji coba berakhir mahasiswa diberi kesempatan mengisi angket secara online serta memberi komentar secara online pula terkait pelaksanaan perkuliahan dengan online problem posing. Jawaban angket dan komentar mahasiswa menunjukkan bahwa mahasiswa memberikan respon yang positif terhadap pelaksanaan perkuliahan dengan online problem posing. Mereka menyatakan lebih termotivasi untuk melakukan diskusi secara online. Pengakuan tersebut cukup logis bila ditelusuri dari gejala psikologis yang timbul sebagai akibat perbedaan karakteristik dari komunikasi bermedia komputer dan komunikasi tatap muka. Komunikasi bermedia komputer (online) relatif bebas konteks. Mahasiswa dapat berkomunikasi tanpa harus memperhatikan kondisi dosen. Apakah dosen sedang sibuk, sedang kesal, atau sedang santai, mahasiswa tetap dapat mengajukan pertanyaan, mengajukan komentar, berkonsultasi, atau mengumpulkan tugas.

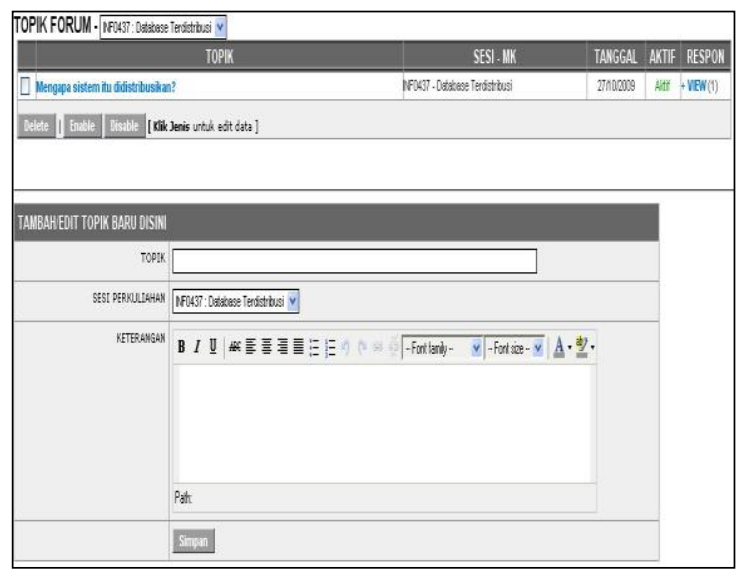

Kondisi seperti ini membuat mahasiswa dapat berpikir dengan bebas dan tenang, tanpa ada tekanan. Suasana tenang mampu mendukung tumbuhnya potensi dasar yang dimiliki mahasiswa.

Kerahasiaan pribadi mahasiswa sangat terlindungi dalam online problem posing. Mahasiswa dapat menggunakan kode rahasia untuk merahasiakan identitas agar pertanyaan, saran, atau keluhan mahasiswa tidak diketahui oleh mahasiswa yang lain. Oleh karena itu, mahasiswa tidak pernah malu untuk mengajukan pertanyaan, komentar, atau saran. Mahasiswa tidak perlu cemas kalau pertanyaannya atau tanggapannya dianggap terlalu ringan atau menyimpang, karena tidak akan ada mahasiswa lain yang dapat mengetahui pertanyaan atau komentar itu milik siapa. Situasi seperti ini akan meningkatkan motivasi belajar mahasiswa karena perhatian mereka terfokus pada permasalahan yang sedang dihadapi. Selain itu mahasiswa merasa mendapat perhatian karena setiap pertanyaan atau komentar yang diberikan selalu akan direspon oleh dosen atau temannya.

Online problem posing tidak secara langsung memberi kesempatan kepada mahasiswa untuk menyampaikan komentar atau pertanyaan, seperti pada komunikasi tatap muka. Ada beberapa mekanisme kerja yang harus dikuasai mahasiswa agar dapat 
menyampaikan komentar, pertanyaan, atau menyerahkan tugas. Mekanisme tersebut sangat terbuka untuk dipelajari oleh mahasiswa, dan sangat menantang mahasiswa untuk mengetahuinya. Oleh karena itu, komunikasi pembelajaran bermedia komputer sangat memberi peluang kepada mahasiswa untuk mengembangkan kreativitasnya.

Temuan sementara penelitian dari hasil uji coba, yang menyatakan bahwa mahasiswa lebih termotivasi untuk berdiskusi dalam online problem posing dari pada problem posing tatap muka didukung oleh temuan-temuan dari beberapa penelitian sebelumnya. Keeler (1996) menemukan bahwa terjadi perubahan iklim belajar, setelah diberlakukan komunikasi pendidikan bermedia komputer. Mahasiswa menjadi lebih aktif, guru dapat lebih memperhatikan siswa secara individu, dan siswa lebih memiliki kebebasan untuk mengeksplorasi bahan kuliah. Askar, Yavuz \& Koksal, seperti dikutip Keeler (1996) dalam penelitiannya menemukan bahwa siswa memiliki sikap positif terhadap pembelajaran bersumber pada komputer. Selanjutnya, Moore \& Taylor (1996) menemukan bahwa komunikasi pembelajaran bermedia komputer mendorong keinginan mencoba, memacu pertukaran ide, meningkatkan partisipasi dalam pembelajaran, dan mengembangkan semangat kerjasama. Memang pada penelitian yang sama Moore dan Taylor juga menemukan bahwa beberapa mahasiswa menemui kesulitan dan merasa terbatasi dalam komunikasi pembelajaran bermedia komputer, karena kurangnya nilai sosial dan terbatasnya kesempatan untuk menerima informasi yang semestinya bisa diterima secara bersama-sama. Akan tetapi keterbatasan tersebut bisa diatasi dengan menciptakan lingkungan sosial yang mendukung interaksi antar individu.

Selain keunggulan akibat media yang digunakan seperti di atas, on-line problem posing juga memberikan keunggulan lain dibandingkan problem posing tatap muka. On-line problem posing yang diitegrasikan dengan asesmen kinerja atau asesmen uraian dapat memberi kesempatan kepada siswa untuk merevisi pertanyaan atau jawaban yang diajukan, sebelum dinyatakan final. Terkait dengan hal ini, Muwanga-Zake (2006) menemukan bahwa asesmen berbasis komputer amat bermanfaat karena siswa sempat merevisi jawaban, memperoleh koreksi dengan segera, dapat mengerjakan kembali tes, dan dapat mengetahui waktu yang tersisa. Selain itu, siswa dapat memperoleh umpan balik dengan segera sehingga mampu melakukan pembelajaran remidi baik dengan bantuan guru maupun tanpa bantuan guru (bekerja sendiri).

Hampir sama dengan temuan

Muwanga-Zake, Williams (2009)

menemukan bahwa pengalaman dan sikap siswa terhadap evaluasi berbasis web amat positif dan mereka lebih memilih eavluasi berbasis web daripada evaluasi tertulis. Ada beberapa keuntungan yang didapat dari evaluasi berbasis web, yaitu umpan balik diperoleh dengan segera, jadwal dapat diatur lebih fleksibel, bebih murah, reliablitas lebih terjamin, fleksibel dari segi waktu dan tempat baik dari sisi siswa maupun guru, penyekoran lebih cepat, keamanan dan kerahasiaan lebih terjamin, catatan sekor siswa dapat disimpan secara otomatis, lebih membuka peluang untuk memonitor kemajuan siswa, mudah mengidentifikasi kesalahan soal, dan mudah menstandarisasikan lingkungan evaluasi.

\section{SIMPULAN DAN SARAN}

Portal web e-learning dengan dikembangkan mengroblem posing pemrograman PHP dan sebagai basis-data pendukung digunakan Mysql. Komponen pendukung lainnya, seperti desain grafis, desain web, dan animasi masing-masing dikembangkan dengan paket program yang relevan. Portal web e-learning dengan fasilitas online problem posing dimanfaatkan dalam proses perkuliahan diterapkan pada 
perkuliahan bilingual mahasiswa Jurusan Pendidikan Matematika RKBI. Fasilitas tersebut dibangun untuk memberi peluang lebih banyak kepada mahasiswa untuk melakukan problem posing dalam bahasa Inggris, agar kualitas perkuliahan lebih meningkat.

Portal web dengan online problem posing telah diujicoba terbatas dengan melibatkan beberapa orang mahasiswa. Mahasiswa memberikan respon yang positif terhadap pelaksanaan perkuliahan dengan online problem posing. Mereka menyatakan lebih termotivasi untuk melakukan diskusi secara online. Pengakuan tersebut cukup logis bila ditelusuri dari gejala psikologis yang timbul sebagai akibat perbedaan karakteristik dari komunikasi bermedia komputer dan komunikasi tatap muka. Komunikasi bermedia komputer (online) relatif bebas konteks. Mahasiswa dapat berkomunikasi tanpa harus memperhatikan kondisi dosen. Apakah dosen sedang sibuk, sedang kesal, atau sedang santai, mahasiswa tetap dapat mengajukan pertanyaan, mengajukan komentar, berkonsultasi, atau mengumpulkan tugas. Kondisi seperti ini membuat mahasiswa dapat berpikir dengan bebas dan tenang, tanpa ada tekanan. Suasana tenang mampu mendukung tumbuhnya potensi dasar yang dimiliki mahasiswa.

Pembelajaran bilingual sedikit memaksa mahasiswa untuk mengajukan pertanyaan atau memberi tanggapan dalam bahasa Inggris. Mahasiswa akan merasa malu kalau bahasa Inggrisnya jelek atau materi pertanyaaan terlalu sederhana. Online problem posing dapat melindungi keranhasiaan pribadi mahasiswa. Mahasiswa dapat menggunakan kode rahasia untuk merahasiakan identitas agar pertanyaan, saran, atau keluhan mahasiswa tidak diketahui oleh mahasiswa yang lain. Oleh karena itu, mahasiswa tidak pernah malu untuk mengajukan pertanyaan. Selain itu, online problem posing tidak terlalu memperhatikan konvensi sosial yang berlaku. Kondisi seperti ini memberi peluang kepada mahasiswa untuk lebih lugas mengajukan pertanyaan atau memberi tanggapan. Oleh karena itu, mahasiswa yang memiliki gangguan komunikasi tatapmuka, seperti pemalu akan sangat terbantu.

Online problem posing sebaiknya dikembangkan dengan lebih intensif, dalam upaya memberikan alternatif strategi pembelajaran yang lebih beragam kepada mahasiswa. Apabila terdapat banyak alternatif pembelajaran, maka mahasiswa akan memiliki peluang untuk memnafaatkan berbagai sumber pembelajaran. Beberapa model pembelajaran yang tersedia diharapkan dapat saling mensubstitusi dan saling melengkapi. Akibatnya, prestasi belajar mahasiswa bisa lebih ditingkatkan. Melalui kesempatan ini disarankan untuk menerapkan pembelajaran dengan online problem posing pada pembelajaran atau perkuliahan bilingaul. Sekalipun masih ada keterbatasan, namun dengan manfaat besar yang ditimbulkan, dan disertai dengan usaha mengatasi keterbatasan yang ada, hasil belajar yang lebih optimum akan bisa dicapai. Selanjutnya, kepada pihak yang tertarik disarankan untuk melengkapi fasilitas online problem posing dengan beberapa layanan lain, seperti evaluasi online, khususnya evaluasi yang bersifat otentik, seperti uraian, kinerja, atau projek lengkap dengan penyekorannya. Dengan demikian pengalaman belajar mahasiswa menjadi lebih terintegrasi, sehingga hasil belajarnya lebih baik.

\section{DAFTAR PUSTAKA}

Anderson, Aneka, Seven Major Challenges for e-learning in Developing Countries, Education Journal of Education and Development Using ICT, Volume 2, Number 4, 2006, ISBN 1814-0556

Bhukuvhani, Crispen dkk., 2010, Pre-service Teachers' use of improvised and virtual laboratory experimentation in Science teaching, International Journal of Education and Development using Information and 
Communication

Technology

(IJEDICT), 2010, Vol. 6, Issue 4, pp.27-38.

Depdiknas, 2010, Rencana Strategis Departemen Pendidikan Nasional 2010-2014, Jakarta:

Depdiknas.go.id English, Lyn D. and James J. Watters, 2004, Mathematical Modelling With Young Children, Proceedings of the 28th Conference of the International Group for the Psychology of Mathematics Education, 2004 Vol 2 pp 335-342

Freire, Paolo, 1996, Pedagogy of the Oppressed, Penguin (First published in 1970).

Ke, Fengfeng \& Christopher Hoadley, 2009, Evaluating Online Community Learning, Education Tech Research Dev (2009) 57:487-491 DOI 10.1007/ s11423-009-9120-2. Published online 28 February 2009 by Association for Educational Communications and Technology (2009). Kotrlik, Joe W. \& Donna H. Redmann, 2009, Technology Adoption for Use in Instruction by Secondary Technology Education Teachers, Journal of Technology Education Vol. 21 No. 1, Fall 2009

Light, Daniel, 2010, Multiple factors supporting the transition to ICT-rich Learning environments in India, Turkey, and Chile, International Journal of Education and Development using Information and Communication

Technology(IJEDICT), 2010, Vol. 6, Issue 4, pp.39-51. 14(1), 19-28. Mabry, Joette Stefl, Michael Radlick \& William Doane, 2010, Can You Hear Me Now? Student voice: High school
\& middle school students' perceptions of teachers, ICT and learning, International Journal of Education and Development using Information and Communication Technology (IJEDICT), 2010, Vol. 6, Issue 4, pp.64-82.

McKnight, Cliff dkk., 1988, "User-Centered Design of Hypertext/Hypermedia for education", Educational Communications and Technology, ed. David H. Jonassen, London: Prentice Hall International

Moore, David M. \& C. David Taylor, 1996, Student Participation, Interaction, and Regulation in A Computer Mediated Communication Environment, Journal of Computing research, Vol. 14(3)

Muwanga-Zake, J.W.F., 2006, Applications of computer-aided assessment in the diagnosis of science learning and teaching, Education Journal of Education and Development Using ICT, Volume 2, Number 4, 2006, ISBN 1814-0556

Silver, E. A., 1994,. On mathematical problem solving. For the Learning of Mathematics.

Sofos, Alivisos \& Appostolos Kostas, 2009, Pedagogically-Oriented Evaluation Criteria for Web Resources, eLearning Papers, www.elearningpapers.eu, No 17, December 2009, ISSN 1887-1542

Xia, Xiaogang, Chuanhan Lü, and Bingyi Wang, 2008, Research on Mathematics Instruction Experiment Based Problem Posing, Journal of Mathematics Education, December 2008, Vol. 1, No. 1, pp.153-163. 